\title{
Antibodies in milk
}

\author{
D. B. L. McClelland \\ Edinburgh and South-East Scotland Regional Blood Transfusion Service, Royal Infirmary, \\ Edinburgh EH3 9HB, U.K.
}

\section{Introduction}

Both in clinical practice and in the scientific literature human milk is often treated as though its only important properties were the volume in which it is produced and its nutritional composition in terms of fat, carbohydrate and protein content. Milk which has the misfortune to get to babies by some indirect route is frequently insulted by pasteurizing or boiling, treatments which certainly damage the functional properties of many of its constituent proteins and cells. From an immunologist's viewpoint, human milk represents a fascinating blend of biologically active molecules and living cells which challenge one to explore their origin, control and biological importance.

It is not a new observation that milk is important to the immunity of the neonate. In the nineteenth century it was known that pregnant sheep vaccinated against cowpox gave birth to newborn lambs who were immune and that vaccinial immunization of mothers led to immunity in their infants, but it was not clear how or when the immunity was transmitted-across the placenta or via the milk, and whether, if it was related to antibodies in the milk, these were absorbed into the circulation or acted locally in the gut. By the 1920's it had been shown that, in newborn calves, deprivation of colostrum was lethal. Three-quarters of calves which were deprived of colostrum died of septicaemia and a single feed of colostrum was enough to protect them. This finding has been amply confirmed for domestic animals, and there have been many studies of human babies that show beyond doubt that breast-fed infants have a lower attack rate for a wide variety of infective problems (Chandra, 1979). It seems reasonable to conclude that at least part of this protection is a direct result of the infant receiving immune protective factors in milk and is not simply a result of nutritional factors or the avoidance of contaminated artificial feeds.

Some of the many antimicrobial properties of milk and factors in milk which are candidates to influence microbial growth are listed in Table 1 (McClelland, McGrath \& Samson, 1978). The antibodies in milk are exciting protective factors to study because they are specific for particular foreign agents and are susceptible to manipulation by immunization, but one should not be obsessed with antibodies to the exclusion of other constituents. For example, lactoferrin, lysozyme and lactoperoxidase are all potent inhibitors of the growth of many bacteria and there are non-antibody virus inhibitors in milk which are little studied but may be biologically important (Butler, 1979). Milk contains a wide range of antibodies against micro-organisms and foreign proteins. In contrast to serum, in which IgG predominates, the predominant type of antibody in milk is immunoglobulin A (IgA). Furthermore, the IgA in milk is structurally quite different from that in the serum (Tomasi \& Grey, 1972). In serum, IgA is structurally similar to IgG although a small proportion of it consists of a dimeric immunoglobulin, i.e. 2 IgA monomers coupled together by a polypeptide called the J-chain (Text-fig. 1). Milk IgA is predominantly secretory $\operatorname{IgA}$, a dimeric molecule with two additional peptide chains termed $\mathrm{J}$-chain and 
secretory component. Secretory $\operatorname{IgA}$ is found in very low concentrations, if at all, in the serum but is a major constituent of milk and most other external secretions.

Table 1. Properties of human colostrum and milk which may influence microbial flora in the neonate and play a role in preventing infection
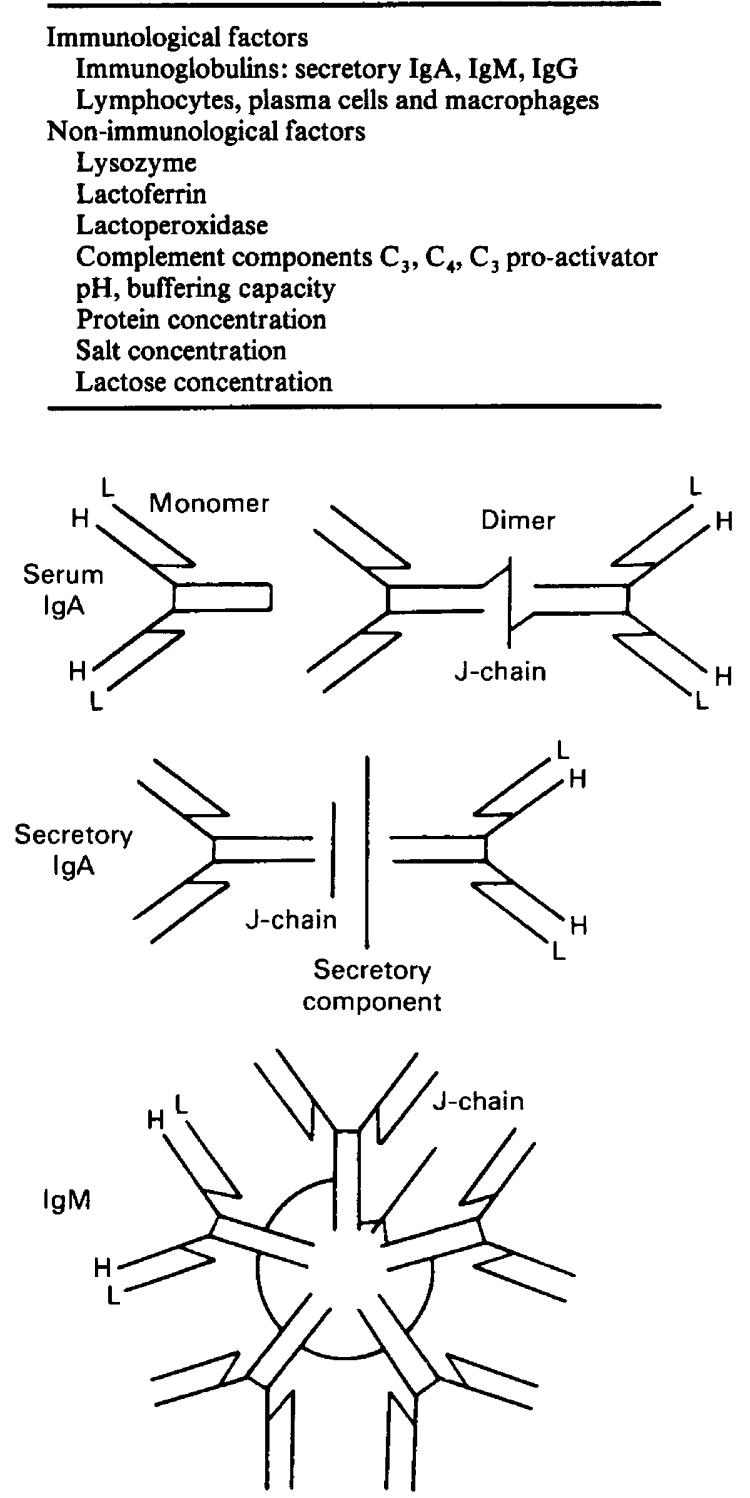

Text-fig. 1. Simplified diagram of the structure of the immunoglobulin classes. $H=$ heavy chain; $\mathrm{L}=$ light chain.

\section{Source of antibody in milk—the mucosal immune system}

It is important to know how the breast is able to produce an antibody response which is of a completely different immunoglobulin class from the antibodies in the blood, and whether there 
are ways of manipulating this antibody response to the benefit of the infant. To discuss this, it is necessary to introduce the concept of a specialized lymphoid system which serves the mucosal surfaces of the body and also involves the mammary gland (Hanson et al., 1978).

The sub-epithelial regions of the mucosal lining of the intestine, together with other mucosal sites and glands such as the parotid which produce external secretions, contain large numbers of plasma cells. These plasma cells produce IgA in the form of a dimeric molecule containing the J-chain and immunohistochemical methods show that both the plasma cells and the surface epithelial cells contain large amounts of IgA. The epithelial cells synthesize secretory component, which is also expressed on the surface of epithelial cells. The dimeric IgA, released by the plasma cells, binds to secretory component on the surface of the epithelial cells and this binding is followed by uptake of IgA and transit through the epithelial cells to the mucosal surface. Secretory component is coupled to the IgA molecule during transit and the final secreted molecule is the intact secretory IgA.

It is also possible that dimeric $\operatorname{IgA}$ which has this capacity to bind secretory component could be produced in a site such as the gut mucosa, but instead of being secreted into the lumen could reach the draining lymphatics, enter the circulation and be transported to another epithelial site, such as the breast, where it could bind to the epithelium and be secreted in the same way. The breast, like the intestinal mucosa, contains plasma cells which synthesize IgA, and IgA can also be detected in the epithelial lining of the ducts themselves. The presence of this distinctive antibody-producing system raises the question of the mechanism by which antibody-producing cells get into mucosal tissues and the breast and what determines the specificity of the antibodies which they produce.

The immunological relationships between the antibody-producing system of the gut and mammary gland are presented in a very simplified form in Text-fig. 2 . Antigen appears to penetrate the gut wall mainly at specialized sites, the Peyer's patches. These are rather like

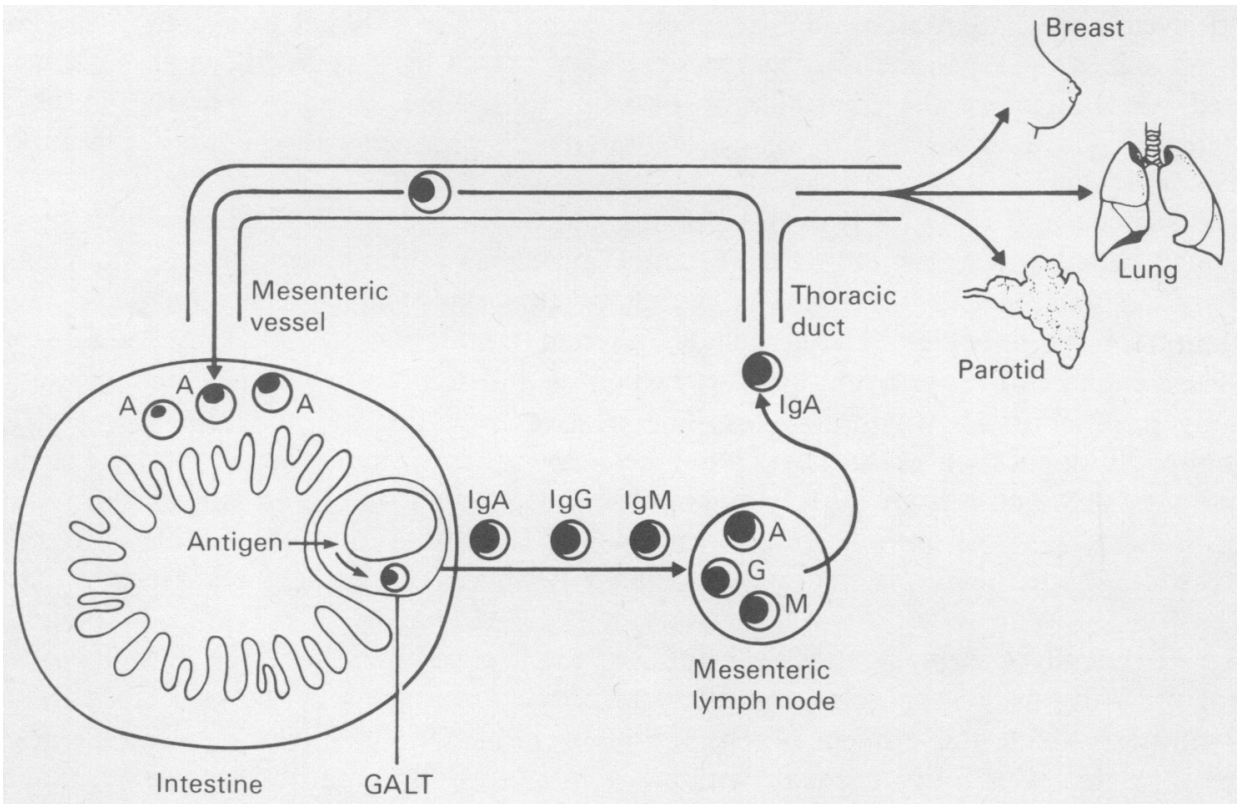

Text-fig. 2. A simplified scheme of the mucosal-associated lymphoid system. B lymphocytes are exposed to antigens in the intestine and travel via the lymphocytes and blood to sites of secretory antibody production, including the mucous membranes of the gastrointestinal and respiratory tracts, and the mammary glands. GALT = gut-associated lymphoid tissues (the Peyer's patches and lymphoid nodules of the appendix). 
lymph nodes in the gut wall, containing the basic equipment of lymph nodes which permits a flow of lymphocytes in and out, with the architecture to allow cellular interactions with antigens. The epithelium which overlies the Peyer's patches is different from the rest of the gut epithelium, being thinner and flatter and allows penetrations by large molecules and even intact micro-organisms.

Lymphocytes enter the Peyer's patches from the circulation, encounter antigen, undergo the cellular interactions which are needed to become sensitized to produce antibody to that antigen, and leave the Peyer's patch via the draining lymphatics, travelling through the mesenteric lymph nodes to the thoracic duct, and thence to the blood. On the way a high proportion of these cells start to evolve into IgA-producing B lymphocytes, making IgA antibodies specifically directed against the relevant antigen. Many of these maturing, IgA-producing cells eventually find their way back to the intestinal mucosa, but they may also become localized in the breast and in other sites where secretory IgA production occurs. The IgA-producing cells localized in these sites mature to become typical plasma cells. It is still far from certain what decides where the cell will eventually arrive and what determines whether a cell will stay in that site and mature or proliferate. One possibility is that the cells which return to a mucous membrane site like the gut are driven to mature and proliferate by meeting again their appropriate antigen and there is some evidence that this happens. However, this mechanism certainly does not explain completely the ability of these cells to mature when they return to a mucosal of glandular site. Firstly, it has been shown that the cells derived from Peyer's patch or a mesenteric lymph node and injected into a recipient animal will find their way back not only to the normal gut but to totally antigen-free fetal gut (Halstead \& Hall, 1972; Moore \& Hall, 1972). Secondly, IgA blast cells from the gut lymphoid tissue will home to the breast in the absence of any evidence of antigen in the breast itself, strongly suggesting that there must be other factors which attract these cells to the glands (Lamm, Roux, Weisz-Carrington, McWilliams \& Phillips-Quagliata, 1977; Roux, McWilliams, Phillips-Quagliata, Weisz-Carrington \& Lamm, 1977). This behaviour of lymphoid cells derived from the gut-associated lymphoid tissues is quite different from that of similar cells from the spleen or a peripheral lymph node. When spleen or peripheral lymph-node cells are injected into a recipient, the great bulk of the antibody-producing cells will end up in the spleen and lymph nodes and these cells will be predominantly producers of $\operatorname{IgG}$ and $\operatorname{IgM}$ antibodies and not IgA.

The scheme in Text-fig. 1 is over-simplified and there is one complication which should be mentioned because it is relevant to the practical problems of immunization to produce a good antibody response in the breast. The gut-associated lymphoid tissues contain a complex population of lymphocytes. These include different populations of T-lymphocytes, some of which are capable of suppressing immune responses and some of which help the generation of antibody production by B-lymphocytes. The relative activation of the suppressor and helper T-lymphocyte population in the Peyer's patches depends to some extent on the type of antigen and the way in which it is given. It is quite possible to feed antigen to an animal and produce a powerful suppression of immune responses which is, at least in part, due to the production of suppressor T-lymphocytes in the gut-associated lymphoid tissues (Elson, Heck \& Strober, 1979).

As an overall concept, it may be helpful to think teleologically of the need for powerful control mechanisms governing the antibody response to antigens in the gut. Since the gut is constantly exposed to the antigens of tens of millions of bacteria and, over the year, kilograms of foreign protein, it is obvious that without some powerful control mechanism the entire metabolism of an animal could become directed to responding immunologically to this constant massive antigenic challenge.

The breast, unlike the gut, does not work to its full capacity all the time, and only turns on its full production mechanisms during lactation. In non-lactating breast secretions, although $\operatorname{IgA}$ is present in high concentrations the total amount of $\operatorname{IgA}$ produced is small because of the small 
volume of secretion. In contrast, in established lactation there is a very substantial output of $\operatorname{IgA}$ into the milk. There must be an effective mechanism to allow the breast to increase its output of secretory IgA antibody in lactation, either by making more antibodies within the breast itself or by efficiently transporting them from the blood into the milk (Halsey, Johnson \& Cebra, 1980).

The non-lactating breast in man and animals contains a small number of IgA-containing plasma cells. There is a dramatic increase in lactation, e.g. in the mouse the number of $\operatorname{IgA}$ cells increases by approximately 900 -fold. This increase is largely due to an increased localization of B-lymphocytes derived from the gut during lactation. When B-lymphocytes prepared from gut-associated lymphoid tissue are injected into a non-lactating animal they can be found in the gut mucosa but very few can be detected in the breast. In contrast, in the lactating animal, large numbers of the injected gut lymphocytes become localized in the breast and are detected as IgA-producing plasma cells.

This effect of pregnancy can be partly imitated by treating virgin mice with oestrogen, progesterone or prolactin (prolactin alone being the most effective single agent). Combined treatment with the three hormones leads to a large increase in the number of IgA plasma cells in the mammary glands in intact animals, and also causes localization of transferred gut lymphocytes in the glands. In contrast, treatment with testosterone stops the normal accumulation of IgA cells in the lactating gland (Weisz-Carrington, Roux, McWilliams, Phillips-Quagliata \& Lamm, 1978). The signal by which reproductive hormones cause these changes in the lymphoid cell migration to the breast is not known. Presumably the target of the hormones is the epithelial cells. Whether these are induced to produce a remotely acting factor, or whether some local change occurs in the breast to promote localization of the lymphocytes is not known.

Normal human milk contains secretory IgA antibodies against a wide range of micro-organisms, e.g. bacteria, bacterial toxins and viruses, as well as antibodies against dietary proteins such as bovine albumin. The type of antibody in the milk reflects, at least to some extent, the immunological experience of the mother. For example, the milk secretions of European and Pakistani mothers have a similar level of antibody against common sero-types of Escherichia coli, but the Pakistani mothers have much higher levels of antibodies to certain enteropathogenic strains of $E$. coli and Cholera vibrios and Cholera toxin (Carlsson et al., 1976; Holmgren, Hanson, Carlsson, Lindblad \& Rahimtoola, 1976). These differences presumably reflect the different microbial exposure of the two groups. In individual patients, rather than in population studies, the effect of gut infection or colonization with the bacteria can also be shown. For example, Salmonella infection in a pregnant mother leads to the production of specific antibody in the milk when lactation begins (Allardyce et al., 1974). Similarly, experimental colonization of a mother's intestine with non-pathogenic $E$. coli, in the last trimester, leads to production of specific IgA antibodies to that organism in the milk (Goldblum et al., 1975).

\section{Immunization to produce specific antibodies in milk}

Looking at these observations and the underlying physiological mechanisms, it is hard to resist the conclusion that nature has equipped the lactating mother with a system for producing in her milk specific IgA antibody directed against micro-organisms which she encounters in her environment and which are therefore likely to pose a threat to the infant. It would therefore be logical to look for ways of immunizing mothers to improve the quality and quantity of protective antibody in the milk, at least in environments where infection is a major hazard to young infants. However, if this approach is to be a practical possibility, it is necessary to find a convenient method of immunization which does not require the mother to undergo intestinal colonization with the micro-organisms, or actual infection; preferably this would involve the use of conventional vaccines. 
In animal studies, it is sometimes possible to boost specific secretory $\operatorname{IgA}$ antibody production in the milk by conventional parenteral immunization. This approach has been used to increase levels of milk antibody to Cholera in Pakistani women. Lactating women were immunized parenterally with killed Cholera vaccine. After 14 days, there was a marked increase in milk antibody content, all of which was $\operatorname{IgA}$, accompanied by a strong serum antibody response. In contrast, antibody production of Swedish mothers could not be boosted in this way, suggesting that there was a need for 'priming' of the immune system by an earlier exposure to the organism (Hanson et al., 1979).

However, there are some complications in this approach to immunization of the breast, because of the powerful control mechanisms which govern the mucosal immune system and this is emphasized by some unexpected and cautionary results of an attempt to immunize mothers to produce polio antibodies in the milk. Mothers who have previously received conventional polio immunization were given either intramuscular vaccine or oral live vaccine. The mothers who received intramuscular vaccine produced an increase in milk antibody to polio. However, mothers immunized with oral polio vaccine consistently showed a striking and prolonged fall in the milk antibody content (Hanson et al., 1979), presumably because the live vaccine in the gut had activated an inhibitory control mechanism. It seems that any efforts to produce protective antibody in milk will require careful study of the type of antigen and the way it is administered before one can be confident of stimulating production of the required milk antibody.

\section{Importance of antibodies in human milk}

Despite the attractiveness of the concept that human milk antibodies are important to the human infant, one must ask what evidence supports it. Secretory IgA from milk has unusual properties which, teleologically, seem well adapted to make it an effective protector of the gut (Tomasi \& Grey, 1972). These properties can be demonstrated in in-vitro systems and to some extent in animal models. There is no doubt that in many experiments with non-human animals, colostrum and milk antibodies can effectively protect infants against challenge with virulent organisms such as gastroenteritis viruses and bacteria which invade the mucosa or act by producing entertoxins. In humans, however, the evidence for the clinical efficacy of milk antibodies, although very suggestive, is still not clear-cut. If breast-fed and bottle-fed infants in many different environments are compared there are fewer infective and allergic problems in the breast-fed infants. For example, Chandra (1979) compared breast- and bottle-fed infants in Canada, attempting to control for as many other factors as possible, and showed strikingly fewer infection problems in the breast-fed group. The findings were similar in Indian infants.

However, these studies show only that breast milk is advantageous; they do not prove that the benefits are due to the antibody content of the milk. Milk contains a host of anti-infective agents and to assess the clinical importance of milk antibody, its effect must be isolated from that of all the other factors. Ideally, a study to establish the importance of milk antibody would compare infection in the infants of two groups of breast-feeding mothers who differ only in that one group has and one group does not have antibodies to the offending organism. An intriguing alternative study would be to make use of the fact that approximately $0.2 \%$ of the population are IgA-deficient. Mothers with IgA deficiency lactate normally and produce milk which contains no IgA but has normal amounts of all the other anti-infective factors. A comparison of the rates of infection in their infants with an appropriate control group, could be an effective way of isolating the biological effects of milk antibody, but because they are rather difficult to find this group of mothers has received little attention. However, in-vitro studies of the anti-bacterial properties of IgA-deficient breast milk show that it is very effective at inhibiting the growth of micro-organisms and the addition of specific secretory $\operatorname{IgA}$ antibody from normal breast milk does not seem to 
increase the anti-bacterial effect of IgA-deficient breast milk (Samson, Mirtle \& McClelland, 1979).

In summary, the lactating human breast is a large scale producer of a form of antibody which is particularly adapted to protecting mucosal surfaces. The breast is part of a generalized mucosal-associated lymphoid system which permits immunization of the breast against organisms experienced by the mother as a result of colonization of the intestine and other sites. This secretory antibody-producing system in the breast is conserved thoughout a very wide range of species and therefore appears to be of evolutionary importance. The possibility now exists for manipulating the production of antibodies in breast milk by immunization. Many other constituents of milk are also important in protecting the neonate against infection. These factors, like antibodies, may be damaged by processing milk: if milk must be fed to infants by an indirect route, it should be treated in ways which preserve these fragile but important components (Björksten et al., 1980).

\section{References}

Allardyce, R.A., Shearman, D.J.C., McClelland, D.B.L., Marwick, K., Simpson, A.J. \& Laidlaw, R.B. (1974) Appearance of specific colostrum antibodies after clinical infection with Salmonella typhimurium. $\mathrm{Br}$. med. J. III, 307-309.

Björksten, B., Burman, L.G., De Chateau, P., Frederikzon, B., Gothefors, L. \& Hernell, O. (1980) Collecting and banking human milk: to heat or not to heat. Br. med. J. 281, 765-769.

Butler, J.E. (1979) Immunologic aspects of breast feeding: anti-infections activity of breast milk. Seminars in Perinatology 3, 255-269.

Carisson, B., Ahlstedt, S., Hanson, L.A., Liden-Janson, G., Lindblad, B.S. \& Sultana, R. (1976) Escherichia coli antibody content in milk from healthy Swedish mothers and mothers from a very low socioeconomic group of a developing country. Acta paediatr. scand. 65, 417-423.

Chandra, R.K. (1979) Prospective studies of the effect of breast feeding on the incidence of infection and allergy. Acta paediatr. scand. 68, 691-694.

Elson, C.O., Heck, J.A. \& Strober, W. (1979) T-Cell regulation of IgA synthesis. In Immunology of Breast Milk, pp. 37-44. Eds P. L. Ogra \& D. Dayton. Raven Press, New York.

Goldblum, R.M., Ahlstedt, S., Carlsson, B., Hanson, L.A., Jodal, U., Liden-Janson, G. \& Sohl-Akerlund, A. (1975) Antibody-forming cells in human colostrum after oral immunisation. Nature, Lond. 257, 797-798.

Halsey, J.F., Johnson, B.H. \& Cebra, J.J. (1980) Transport of immunoglobulins from serum into colostrum. J. exp. Med. 151, 767-772.

Halstead, T.E. \& Hall, J.G. (1972) The homing of lymph-borne immunoblasts to the small gut of neonatal rats. Transplantation 14, 339-346.

Hanson, L.A., Ahlstedt, S., Carlsson, B., Fallstron, S.P., Kaijser, B., Lindblad, B.S., Sohl-Akerlund, A.S. \& Svanborg, E.C. (1978) New knowledge in human milk immunoglobulin. Acta paediatr. scand. 67, 577-584.

Hanson, L.A., Carisson, B., Cruz, J.R., Carcia, B., Holmgren, J., Khan, S.R., Lindblad, B.S., Svennerholm, A.M., Svennerholm, B. \& Uruitia, J. (1979) Immune response in the mammary gland. In Immunology of Breast Milk, pp. 145-154. Eds P.L. Ogra \& D. Dayton. Raven Press, New York.

Holmgren, J., Hanson, L.A., Carlsson, B., Lindblad, B.S. \& Rahimtoola, J. (1976) Neutralising antibodies against Escherischia coli and vibrio cholerae enterotoxins in human milk from a developing country. Scand. J. Immunol. 5, 867-871.

Lamm, M.E., Roux, P., Weisz-Carrington, P., McWilliams, M. \& Phillips-Quagliata, J.M. (1977) Cellular origin of the IgA in milk. Protides Biol. Fluids Proc. Colloq. Bruges 25, 835-848.

McClelland, D.B.L., McGrath, J. \& Samson, R.A. (1978) Antimicrobial factors in human milk. Acta paediatr. scand., Suppl. 271, 1-20.

Moore, A.R. \& Hall, J.G. (1972) Evidence for a primary association between immunoblasts and the small gut. Nature, Lond. 239, 161-162.

Roux, M.E., McWilliams, M., Phillips-Quagliata, J.M., Weisz-Carrington, P. \& Lamm, M.E. (1977) Origin of IgA secreting plasma cells in the mammary gland. J. Exp. Med. 146, 1311-1322.

Samson, R.R., Mirtle, C. \& McClelland, D.B.L. (1979) Secretory IgA does not enhance the bacteriostatic effects of iron or vitamin $\mathbf{B}_{12}$ binding protein in human colostrum. Immunology 38, 367-373.

Tomasi, T.B. \& Grey, H.M. (1972) Structure and function of immunoglobulin A. Prog. Allergy 16, 181-213.

Weisz-Carrington, P., Roux, M., McWilliams, M., Phillips-Quagliata, J.M. \& Lamm, M.E. (1978) Hormonal induction of the secretory immune system in the mammary gland. Proc. Natn. Acad. Sci. U.S.A. 75, 2928-2932. 